\title{
EXHAUST FLUID INJECTION ANALYSIS OF COMPLETE EXHAUST SYSTEMS OF DIESEL ENGINES
}

\author{
André Bergel $^{1}$ \\ General Motors - Global Propulsion Systems - South America ${ }^{12}$ \\ E-mail: andrebergel84@yahoo.com.br ${ }^{1}$
}

\section{SUMMARY}

This analysis takes into account the complete exhaust system (turbo, DOC, DPF, SCR, Muffler, mixers and pipes) to evaluate one pulse injection of exhaust fluid for Selective Catalytic Reduction (SCR). This procedure can guide us in order to evaluate the efficiency of injection mixture, evaporation, fluid film formation and NOx conversion for a Diesel engine. It was used real conditions of load for engine exhaust flow, temperature, turbine rotation, mass flow of exhaust fluid, spray characteristics, etc.

\section{INTRODUCTION}

Nowadays, in order to meet stringent emission norms, a diesel after treatment system consists of various components: diesel oxidation catalyst (DOC), selective catalytic reduction (SCR), diesel particulate filter (DPF), and others.

In these systems, SCR play an important role in order to reduce NOx from engine exhaust emissions. A diesel exhaust fluid (DEF) injector, some mixers and the catalyst, composes SCR systems.

Computational fluid dynamics (CFD) plays an important role in performance evaluation of all exhaust system components, reducing costs of physical tests and providing reliable results in order to make the best choice in terms of performance, quality and cost.

\section{METHODOLOGY}

\subsection{Exhaust Lines Layout and Load Cases}

In this analysis were used two different exhaust line geometries: first is for medium size engines (ME) and second is for large size engines (LE) for passenger cars.

The ME layout (Figure 01) is composed by DOC, DPF and two SCR's, while LE layout (Figure 02) is composed by DOC, two SCR's, DOC and DPF.Also, in the geometries are 
included mixers (one mixer in ME and two mixers in $\mathrm{LE}$ ), used to promote a better mixture and improve evaporation of injected urea and fuel, injector house, etc.

In Table 01 and 02 can be seen a normalized summary of load cases used in the analysis. The load cases are averaged values measured in the exhaust system when the complete car is submitted to some emissions validation procedure, like FTP75 or US06 ${ }^{[2]}$ federal standard procedures, representing a percent of the full load condition. The normalization procedure is necessary in order to do notdisclose sensible data from GM engines and suppliers. It was normalized separately for each analyzed engine (relative to full load conditions, except DEF injection rate), and for each property or result evaluated.

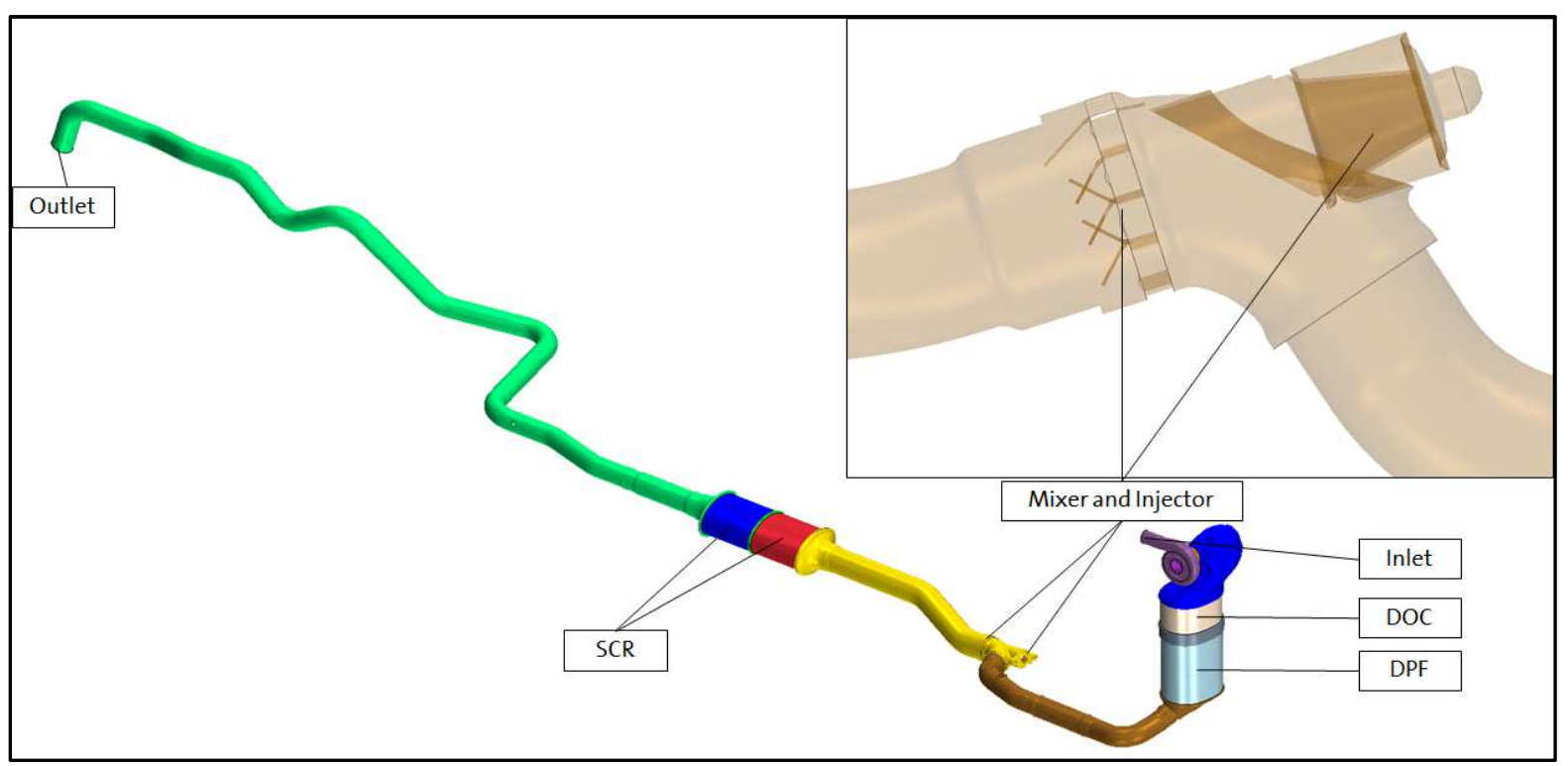

Figure 01 - ME exhaust system layout.

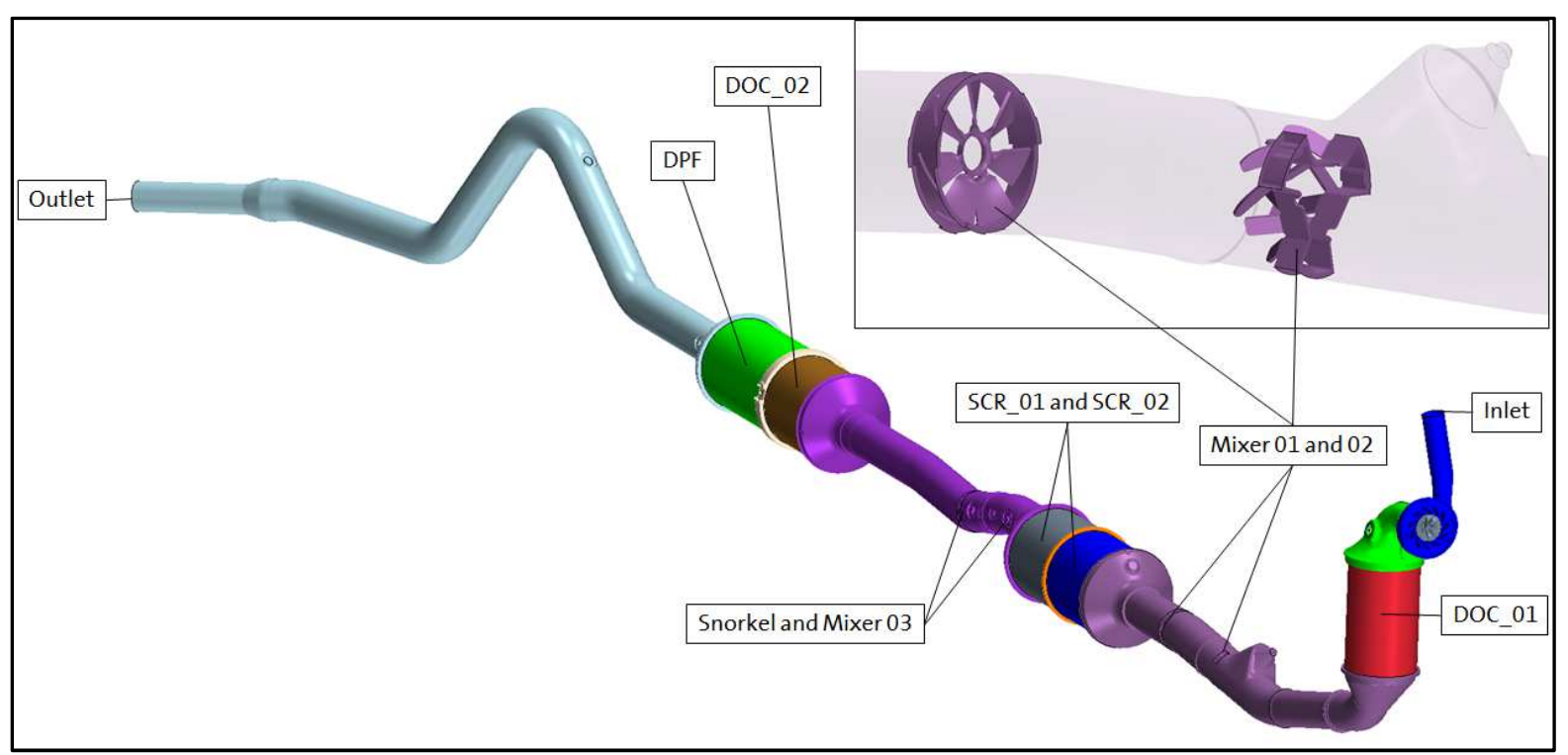

Figure $02-$ LE exhaust system layout. 
Table 01 - Normalized load cases used in ME analysis.

\begin{tabular}{|c|c|c|c|c|}
\hline \multicolumn{2}{|c|}{ ME - Normalized Values } & Case 01 & Case 02 & Case 03 \\
\hline Mass Flow Rate & $\mathrm{kg} / \mathrm{h}$ & 0.1000 & 0.2500 & 0.5000 \\
\hline Inlet NOx Concentration & $\mathrm{PPM}$ & 0.2500 & 0.7500 & 1.0000 \\
\hline DEF Injection Rate & $\mathrm{mg} / \mathrm{s}$ & 0.0500 & 0.3738 & 1.0000 \\
\hline Total Temperature near Injector & $\mathrm{K}$ & 0.2842 & 0.2842 & 0.2842 \\
\hline Turbo Rotational Speed & $\mathrm{RPM}$ & 0.1826 & 0.5710 & 0.7080 \\
\hline Turbo VGT Position & $\circ$ & 0.3733 & 0.4188 & 0.8006 \\
\hline Outlet Static Pressure & $\mathrm{kPa}$ & \multicolumn{3}{|c}{103.8250} \\
\hline
\end{tabular}

Table 02 - Normalized load cases used in LE analysis.

\begin{tabular}{|c|c|c|c|c|}
\hline LE - Normalized Values & Case 01 & Case 02 & Case 03 \\
\hline Mass Flow Rate & $\mathrm{kg} / \mathrm{h}$ & 0.0973 & 0.2500 & 0.5000 \\
\hline Inlet NOx Concentration & $\mathrm{PPM}$ & 1.0000 & 1.0000 & 1.0000 \\
\hline DEF Injection Rate & $\mathrm{mg} / \mathrm{s}$ & 0.2999 & 0.7199 & 1.0000 \\
\hline Total Temperature near Injector & $\mathrm{K}$ & 0.2981 & 0.2683 & 0.2981 \\
\hline Turbo Rotational Speed & $\mathrm{RPM}$ & 0.2452 & 0.4679 & 0.7424 \\
\hline Turbo VGT Position & $\circ$ & 0.2157 & 0.4610 & 0.6415 \\
\hline Outlet Static Pressure & $\mathrm{kPa}$ & \multicolumn{3}{|c}{101.3250} \\
\hline
\end{tabular}

\subsection{Boundary Conditions}

In this approach, inlet condition was modeled as constant mass flow at a fixed temperature, using air as work fluid. Also, outlet condition is the atmosphere status condition, $300[\mathrm{~K}]$ and 103.825/101.325 [kPa] (ME/LE).

Walls was modeled using a free convection approach of heat exchange between environment and exhaust gas, providing a suitable heat transfer coefficient and ambient temperature.

Once temperature boundary condition was measurednear DEF injector, it is necessary to correcttemperature at turbine inlet in order to match this value.

Turbine geometry was included in the model in order to take into account the flow swirl due to turbine wheel rotation, modeled using Moving Reference Frame (MRF) approach.

\subsection{Physics Modeling}

Exhaust gaswas modeled as air with ideal gasapproach, using $k$ - $w$ turbulence model and Darcy's law to porous media, and some properties was changed to mimic the exhaust gas behavior, like molar weight, etc. 
In addition, DEF injection was modeled as injection points, once per each injector hole using spray characterization data, like: maximum mass flow, opening angle, velocity distribution, Sauter Mean Diameter (SMD) distribution, etc. The DEF was modeled as water, changing properties to mimetic DEF behavior, like density, surface tension, viscosity, etc.

The after treatment components are modeled as a porous media, providing lengthwise coefficients of pressure drop for each component. Porous media coefficients used in the analysis are normalized and provided in the Table 03 , where $\alpha$ and $\beta$ are variables of software to simulate porous media.

Table 03 - Normalized values of porous media cefficients used in analysis.

\begin{tabular}{|c|c|c|c|c|}
\hline \multirow{2}{*}{ Component } & \multicolumn{2}{|c|}{ ME } & \multicolumn{2}{c|}{ LE } \\
\cline { 2 - 5 } & Normalized $\alpha$ & Normalized $\beta$ & Normalized $\alpha$ & Normalized $\beta$ \\
\hline DOC 01 & 0.6119 & 0.2713 & 0.2906 & 0.2614 \\
\hline DOC 02 & --- & --- & 0.1864 & 0.1286 \\
\hline DPF & 1.0000 & 1.0000 & 0.7576 & 0.4586 \\
\hline SCR 01 & 0.1259 & 0.2712 & 0.3430 & 0.1592 \\
\hline SCR 02 & 0.1259 & 0.2712 & 0.3430 & 0.1592 \\
\hline
\end{tabular}

It was used a commercial numerical code to solve the mass, momentum and energy conservation equations, turbulence models and all physics modeling in these analysis. STAR$\mathrm{CCM}+$ is a well-recognized solution to tackle problems involving complex geometries and multi-physics problems ${ }^{[3]}$.

\subsection{Meshing Setup and Details}

It was used a polyhedral mesh, using prismatic elements near the walls, extruding the inlet and outlet faces to correctly apply the boundary conditions ${ }^{[4]}$. There are about 1.4 million elements in ME models and 2.59 million in LE models, including extrusions, prismatic and polyhedral elements.

There are some refinements zones in the model, like sensors, variable angle blades, mixers faces and in faces close each one, required to improve quality mesh metrics, reduce convergence time and improve results quality.

\section{RESULTS}

The DEF injection and evaporation analysis can help to understand the behavior of the droplets, evaporation rate, liquid film formation, etc. DEF distribution in the SCR inlet shows the quality of mixing with exhaust gas due to mixers presence. 


\subsection{DEF and NOx Distribution at SCR Porous Media Inlet Section}

DEF mas flow distribution is composed of vapor, liquid and combined, showed in the Figures 03 to 05 , below. NOx mass flow distribution is showed in the Figure 06.
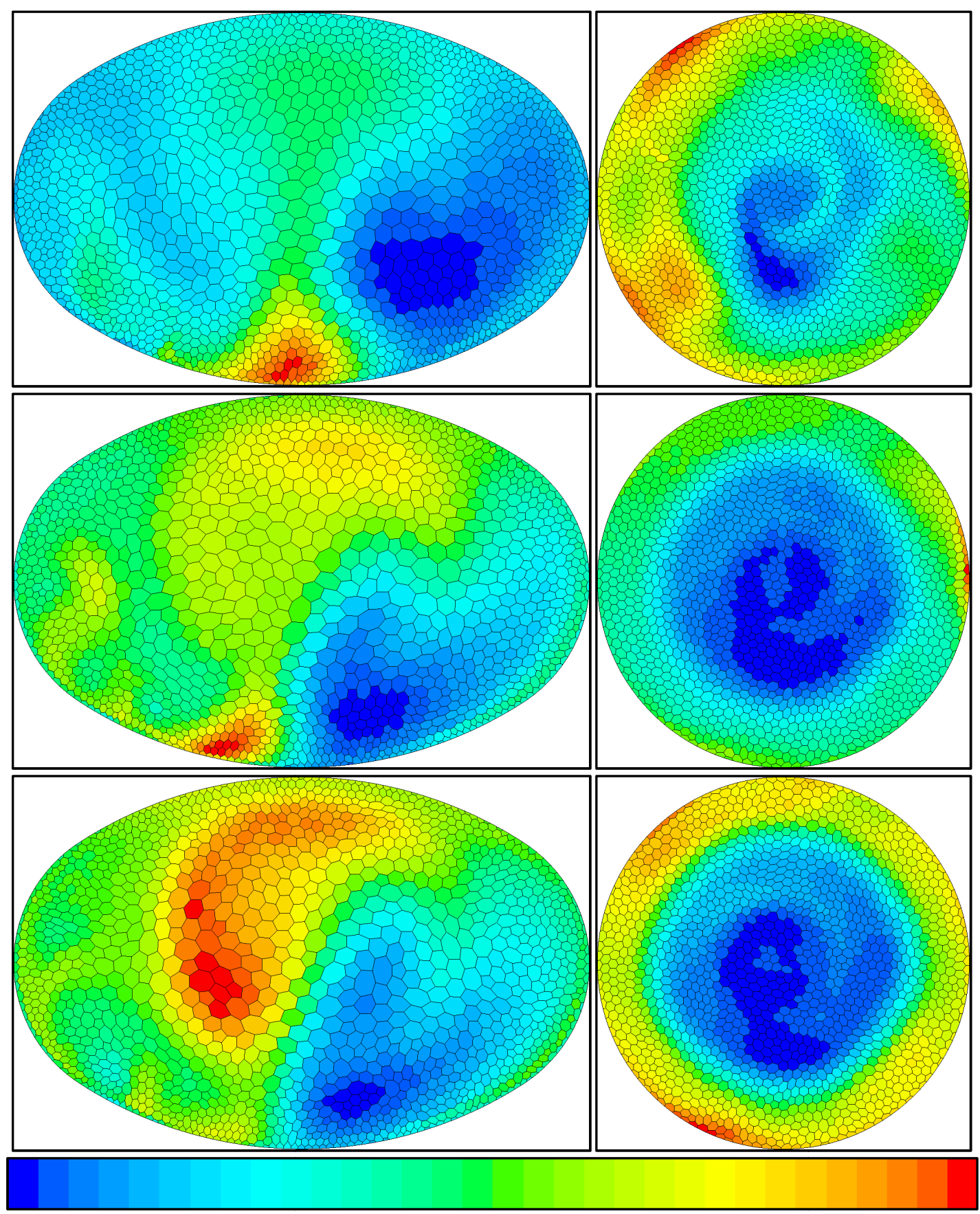

Figure 03 - DEF vapor mass flow distribution for ME (L) and LE (R), all cases in order (10, 25 and $50 \%$ of Full Load). 

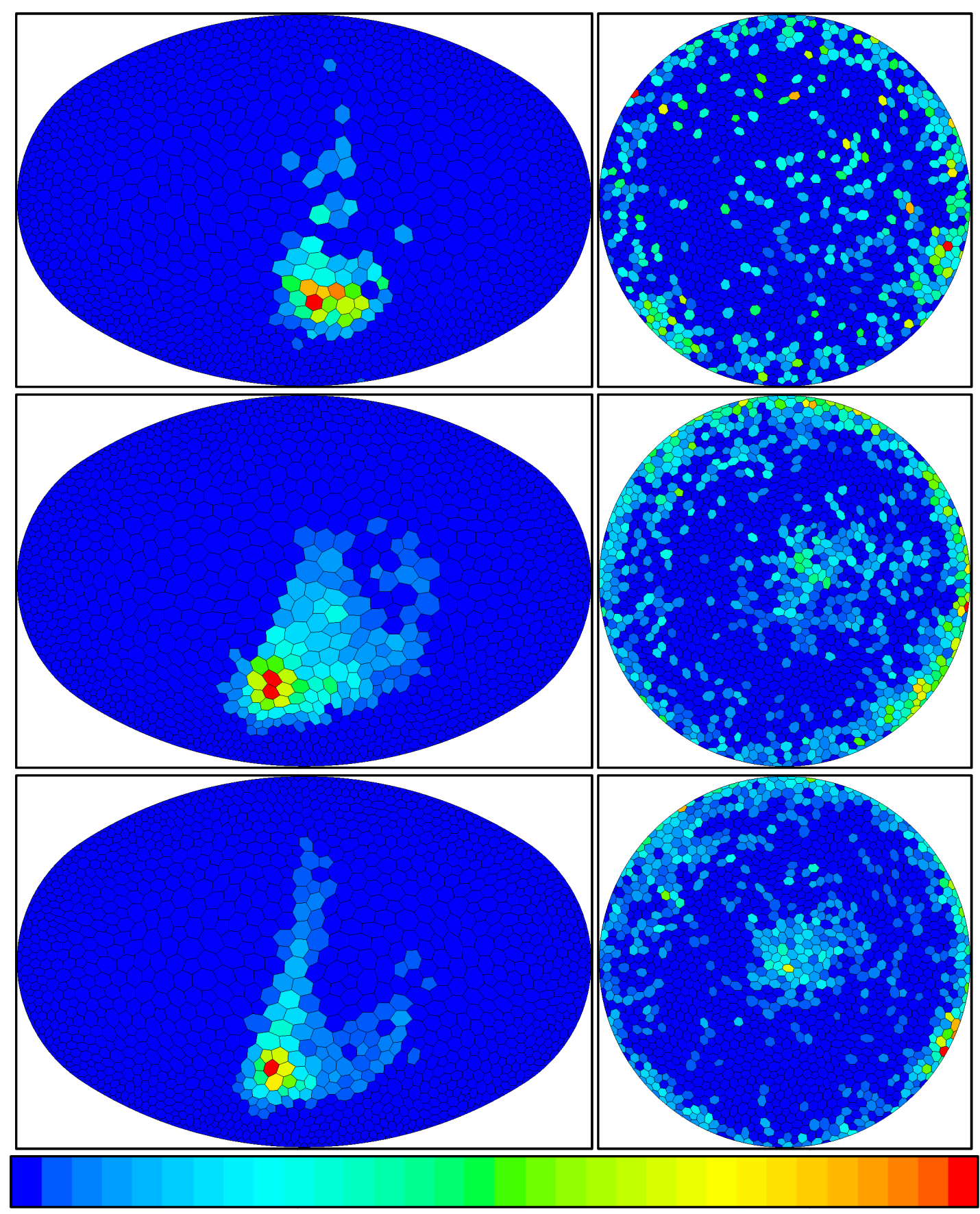

Figure 04 - DEF liquid mass flow distribution for ME (L) and LE (R), all cases in order (10, 25 and $50 \%$ of Full Load). 

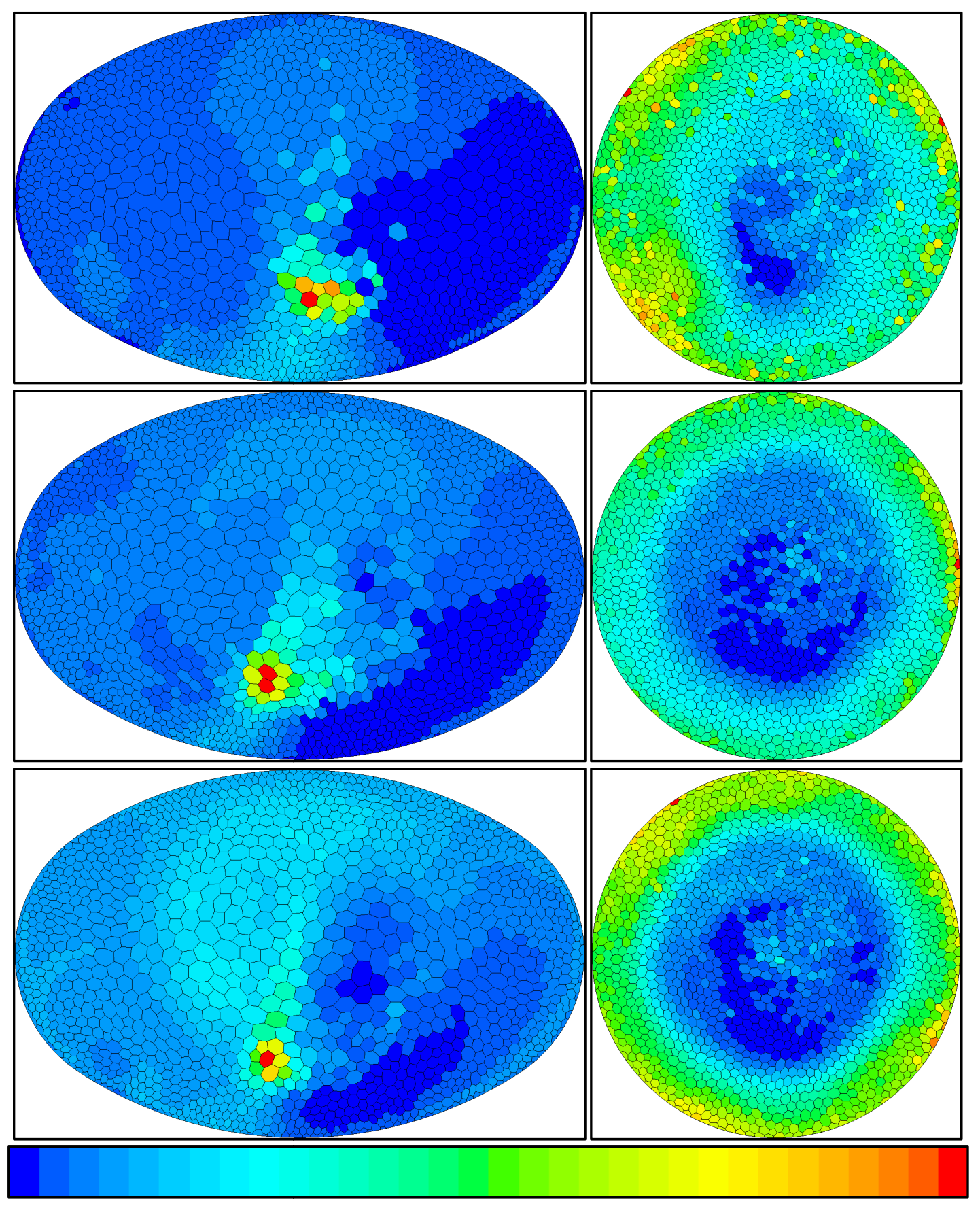

Figure 05 - DEF total mass flow (Vapor+Liquid) distribution for ME (L) and LE (R), all cases in order (10, 25 and 50\% of Full Load). 

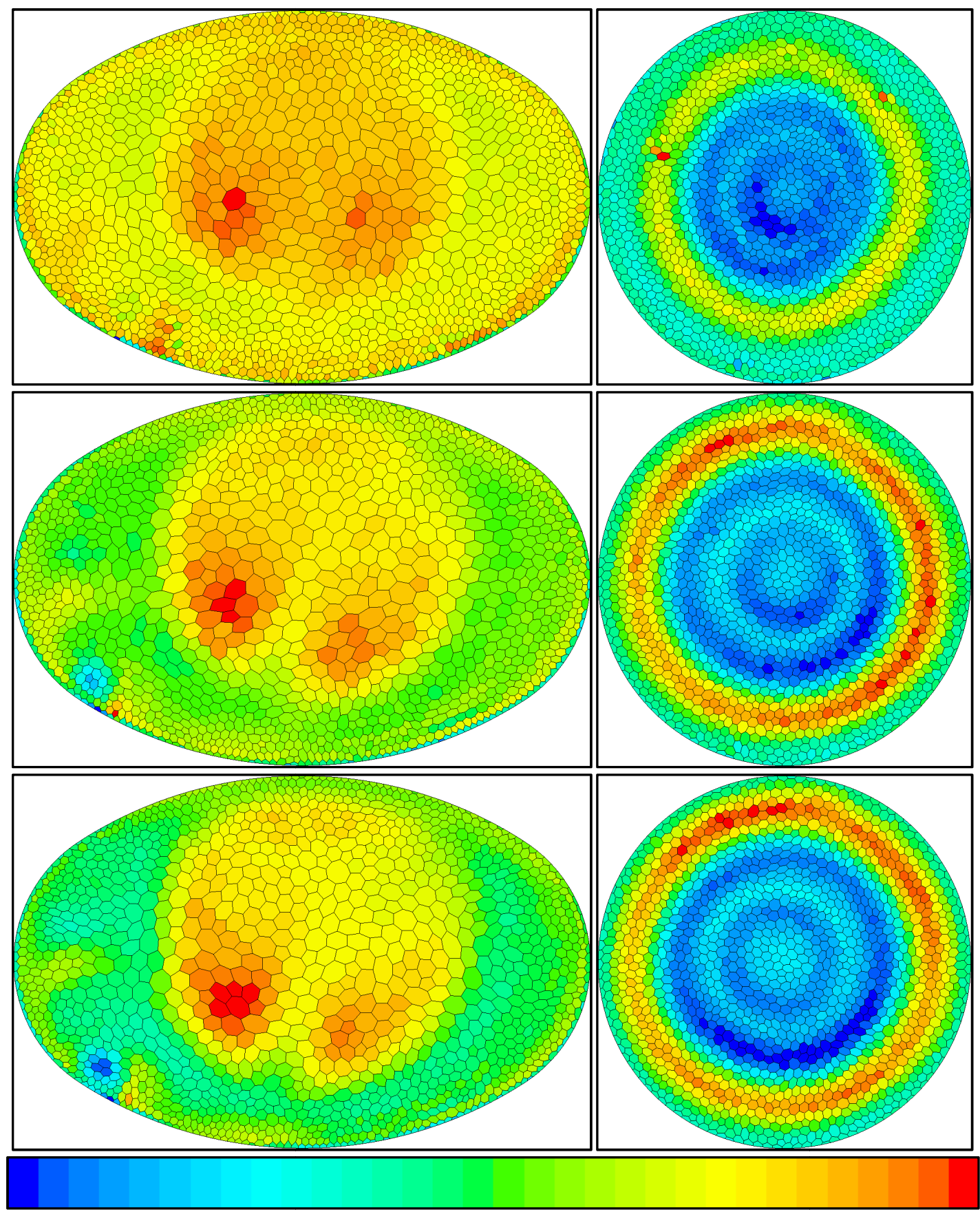

Figure 06 - NOx mass flow distribution for ME (L) and LE (R), all cases in order (10, 25 and $50 \%$ of Full Load).

From these results, we can note that DEF and NOx mass flow are non-uniform. In the DEF total flow, can be noticed that some droplets are impinging the inlet section of SCR, reducing the global NOx conversion efficiency. In other way, the NOx mass flow are distributed over all section, with small differences between maximum and minimum values. 


\subsection{Averaged Alpha Ratio at SCR Porous Media Inlet Section}

Alpha ratio is related to the ratio between DEF quantity into the cell and DEF quantity needed to convert all NOx. As close alpha ratio value is close to unitary value, it is better.
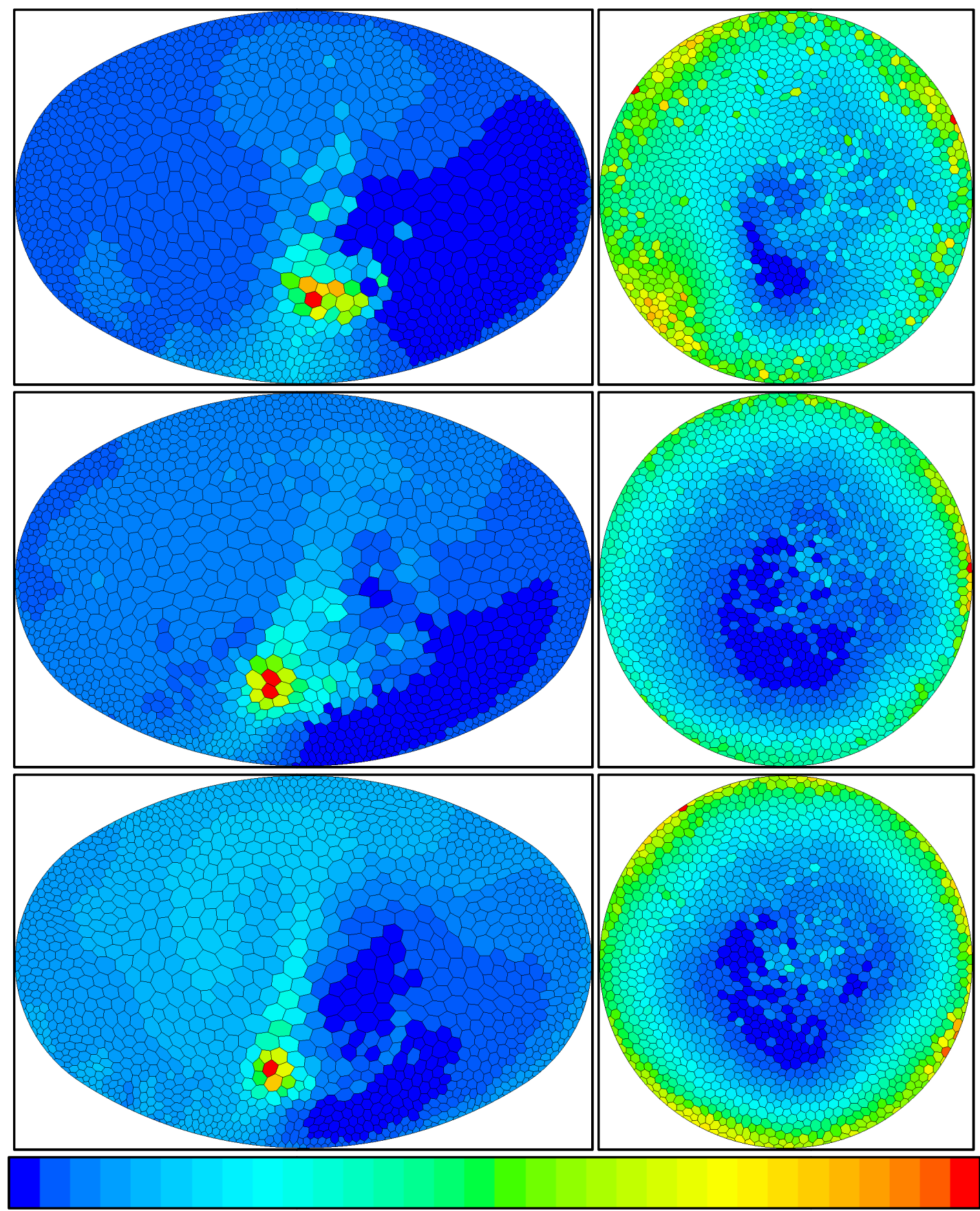

Figure 07 - Cycle Averaged Alpha Ratio distribution for ME (L) and LE (R), all cases in order (10, 25 and $50 \%$ of Full Load).

It can be noticed that the region with droplets impingement is concentrating the alpha ratio maximum values for the ME engine. There are no very high concentration zones into the LE engine. 


\subsection{DEF and NOx Slip Distribution at SCR Porous Media Inlet Section}

The DEF and NOx Slip concentration at inlet section of SCR are important in order to show zones where there are more NOx than DEF or more DEF than NOx.
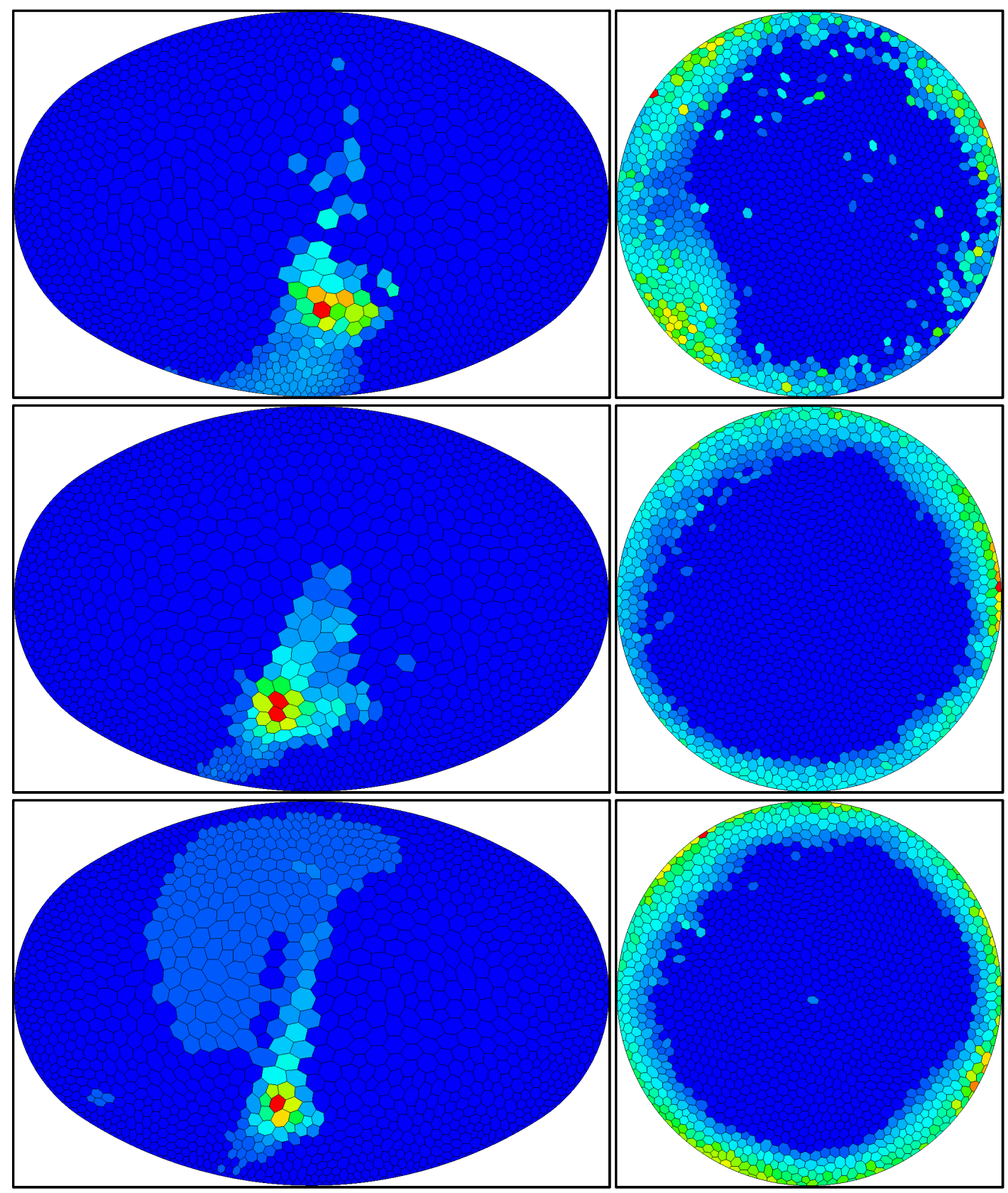

Figure 08 - Slip DEF distribution for ME (L) and LE (R), all cases in order (10, 25 and 50\% of Full Load). 

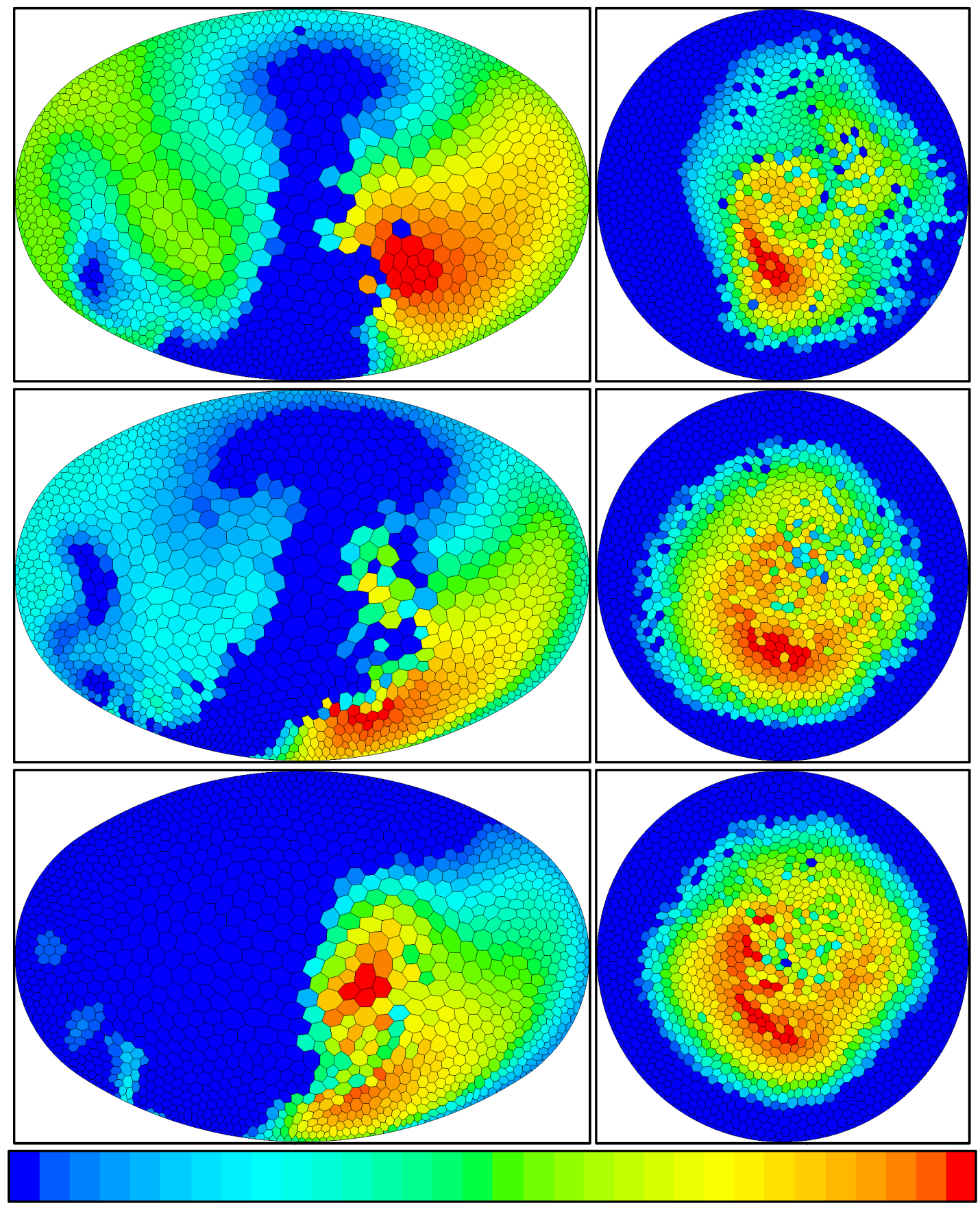

Figure 09 - Slip NOx distribution for ME (L) and LE (R), all cases in order (10, 25 and 50\% of Full Load). 

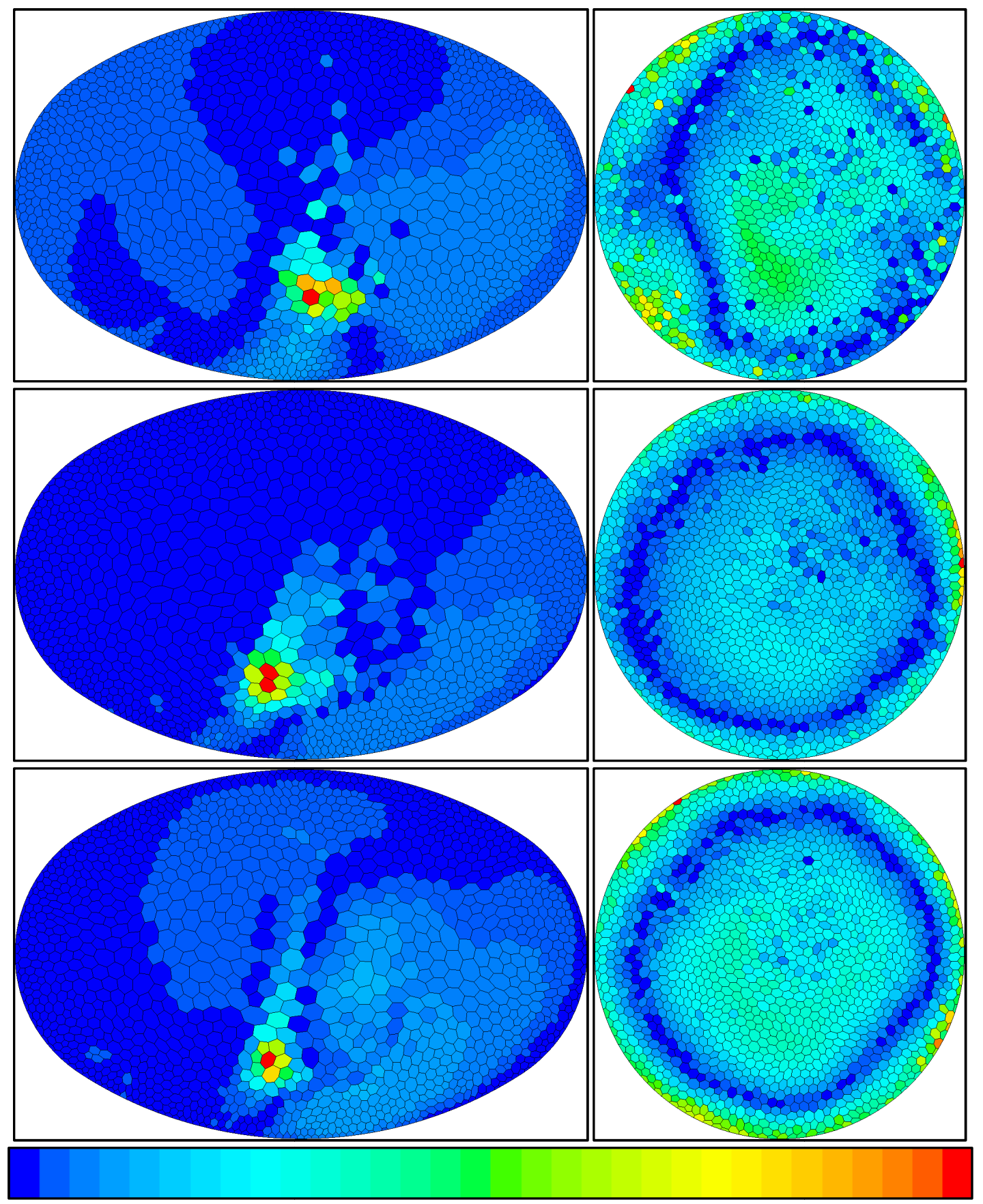

Figure 10 - Slip DEF and NOx distribution for ME (L) and LE (R), all cases in order (10, 25 and $50 \%$ of Full Load).

As expected, we can see that DEF and NOx slipping into the SCR inlet section are opposites to each one. Once more in the ME engine, droplets impinging at inlet section shows a bad distribution of DEF, reducing global NOx conversion efficiency. 


\subsection{Cycle Averaged Mass Flow of DEF at First Mixer Section}

The cycle averaged mass fraction of DEF at first mixer section can show concentration zones of DEF and unused parts of the mixer. It can be view in the Figure 11, below.
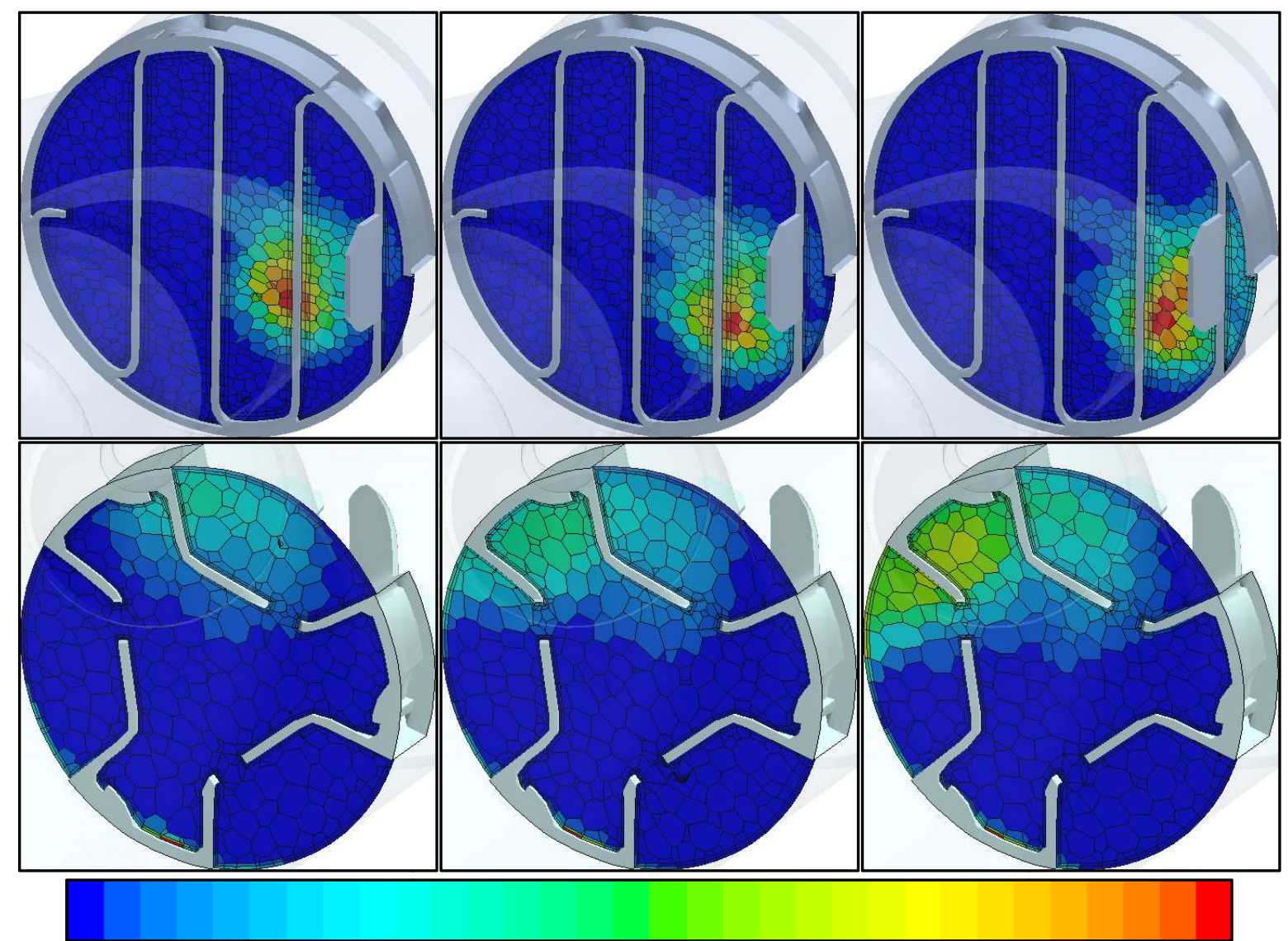

Figure $11-\mathrm{ME}$ (Up) and LE (Down) cycle averaged mass flow of DEF at first mixer cross section.

In these results, we can see that not all cross section of first mixer is being used to droplets breakup, for both engines. It can result in a bad tradeoff between evaporation and generated pressure loss due to mixer, once some blades are less used to

\section{CONCLUSIONS}

This methodology can provide efficient ways to improve mixture of DEF into exhaust gas to rise system NOx conversion. It provide information about DEF and NOx mass flow distribution, averaged alpha ratio distribution and Slipping DEF and NOx at SCR inlet section, in order to identify improvements in geometry to achieve better global conversion efficiency.

In addition, CFD analysisis able to reduce test costs, providing reliable results faster than physical methodology, with high quality and accuracy. 


\section{ACKNOWLEDGMENTS}

To GM GPS South America and North America for providing physical and virtual space for the analysis.

To Chi-Jou Wang (GMNA) and Ivan Flaminio Cozza (GME) for the support with his great knowledge and experience.

\section{REFERENCES}

[1] Heywood, John, Internal Combustion Engine Fundamentals, McGraw Hill, New York, NY, 1988.

[2] www.epa.gov, accessed on 27-May-2016.

[3] www.cd-adapco.com, accessed on 27-May-2016.

[4] Schlichting, H., Boundary Layer Theory, $7^{\text {th }}$ Edition, McGraw Hill, New York, NY, 1979. 